nephron

Practice
Nephron 2015;131:161-166

DOI: $10.1159 / 000440968$
Received: May 18, 2015

Accepted after revision: September 1, 2015 Published online: November 6, 2015

\title{
Administration of Ferric Citrate Hydrate Decreases Circulating FGF23 Levels Independently of Serum Phosphate Levels in Hemodialysis Patients with Iron Deficiency
}

\author{
Akira Iguchi $^{a, c}$ Junichiro J. Kazama, ${ }^{a}$ Suguru Yamamoto ${ }^{a}$ \\ $K_{\text {Kazuhiro Yoshita }}^{a, c}$ Yasuo Watanabe ${ }^{c}$ Noriaki lino $^{a}$ Ichiei Narita ${ }^{a}$ \\ a Division of Clinical Nephrology and Rheumatology, Niigata University Graduate School of Medical and Dental \\ Sciences and ${ }^{b}$ Division of Blood Purification Therapy, Niigata University Medical and Dental Hospital, Niigata, and \\ 'Department of Internal Medicine, Ojiya General Hospital, Ojiya, Japan
}

\section{Key Words}

Fibroblast growth factor 23 - Ferric citrate hydrate .

Sevelamer- $\mathrm{HCl} \cdot$ Parathyroid hormone $\cdot 1,25(\mathrm{OH})_{2}$

vitamin $\mathrm{D} \cdot$ Ferritin

\begin{abstract}
Background/Aim: Dietary phosphate intake and vitamin D receptor activator (VDRA) regulate fibroblast growth factor 23 (FGF23); iron may modulate FGF23 metabolism. We aimed to determine whether oral iron supplementation influences serum FGF23 concentration in hemodialysis (HD) patients, while excluding the effect of dietary phosphate intake. Methods: This prospective study enrolled 27 maintenance HD patients with iron deficiency and hyperphosphatemia treated with sevelamer- $\mathrm{HCl}$. The phosphate binder was changed from sevelamer- $\mathrm{HCl}$ to ferric citrate hydrate $(\mathrm{FCH})$ to maintain constant phosphate levels. VDRA, other phosphate binders, and cinacalcet $\mathrm{HCl}$ were not changed. Serum intact FGF23, C-terminal FGF23 (C-term FGF23), intact parathyroid hormone (PTH), 1,25( $\mathrm{OH})_{2} \mathrm{D}$ and other parameters were monitored for 12 weeks. Results: Serum phosphate levels $(5.89 \pm 1.45 \mathrm{mg} / \mathrm{dl}$ at baseline, $5.54 \pm 1.35 \mathrm{mg} /$ $\mathrm{dl}$ at 12 weeks) and $1,25(\mathrm{OH})_{2} \mathrm{D}$ levels were unchanged. Se-
\end{abstract}

rum ferritin levels increased from $25.6 \pm 24.3 \mathrm{ng} / \mathrm{ml}$ at baseline to $55.8 \pm 33.5 \mathrm{ng} / \mathrm{ml}$ at 12 weeks with $\mathrm{FCH}$ administration. Serum intact FGF23 and C-term FGF23 levels significantly decreased at 12 weeks compared with baseline $(2,000$ $(1,300.0-3,471.4)$ to $1,771.4(1,142.9-2,342.9) \mathrm{pg} / \mathrm{ml}, \mathrm{p}=$ 0.01 , and $1,608.7(634.8-2,308.7)$ to $1,165.2(626.1-1,547.8)$ $\mathrm{RU} / \mathrm{ml}, \mathrm{p}=0.007$, respectively); serum intact PTH levels significantly increased (96 (65-125) to $173(114-283) \mathrm{pg} / \mathrm{ml}, \mathrm{p}<$ $0.001)$. Conclusions: Oral FCH administration decreased serum intact FGF23 and C-term FGF23 levels and increased intact PTH levels; phosphate and $1,25(\mathrm{OH})_{2} \mathrm{D}$ levels were unchanged. Oral $\mathrm{FCH}$ administration to treat iron deficiency is a possible strategy for reducing serum FGF23 levels independent of phosphate and VDRA. @ 2015 The Author(s)

Published by S. Karger AG, Basel

\section{Background}

Fibroblast growth factor 23 (FGF23) is a bone-derived hormone that plays an important role in systemic mineral handling. Serum FGF23 levels are elevated in chronic kidney disease (CKD) patients [1-5], and in-

\begin{tabular}{|c|c|}
\hline KARGER 125 & (C) 2015 The Author(s) \\
\hline & $1660-8151 / 15 / 1313-0161 \$ 39.50 / 0$ \\
\hline www.karger.com/nef & $\begin{array}{l}\text { This article is licensed under the Creative Commons Attribution- } \\
\text { NonCommercial-NoDerivatives } 4.0 \text { International License (CC BY- } \\
\text { NC-ND) (http://www.karger.com/Services/OpenAccessLicense). } \\
\text { Usage and distribution for commercial purposes as well as any dis- } \\
\text { tribution of modified material requires written permission. }\end{array}$ \\
\hline
\end{tabular}

Dr. Junichiro J. Kazama

Division of Blood Purification Therapy, Niigata University

Medical and Dental Hospital, 1-754 Asahimachi-dori, Chuo-Ku

Niigata 951-8510 (Japan)

E-Mail jjkaz@med.niigata-u.ac.jp 
creased FGF23 levels are associated with a poor prognosis and increased cardiovascular events in these patients [6-9].

FGF23 secretion from osteoblastic cells is regulated by dietary phosphate intake [10], vitamin D receptor activator (VDRA) [11, 12], serum calcium levels [13], and parathyroid hormone (PTH) levels [14]. In addition to these regulating factors, iron has gained increased attention as a possible third factor regulating FGF23 [15]. Recent data from an animal study suggests that iron deficiency stimulates FGF23 transcription in osteocytes [16]. In humans, FGF23 levels are measured by using a C-terminal immunoassay (C-term FGF23). This assay detects both fulllength FGF23 and its C-terminal fragments, which are inversely correlated with iron status $[17,18]$. The level of full-length FGF23 assessed by the intact FGF23 immunoassay (intact FGF23), which measures biologically active FGF23, did not show a correlation with iron status [19]. On the other hand, in autosomal dominant hypophosphatemic rickets, which is characterized by impaired cleavage of intact FGF23, both C-term and intact FGF23 are inversely correlated with iron status [17]. Otherwise, although iron deficiency has been shown to increase FGF23 transcription, intact FGF23 levels do not increase in healthy humans under conditions of iron deficiency, possibly because they have normal FGF23 cleavage function. Moreover, an in vitro study in an osteoblastic cell line demonstrated that iron chelation with deferoxamine increases FGF23 mRNA expression by 20 -fold in association with stabilization of hypoxia inducible factor-1a [16]. Taken together, these results suggest that iron deficiency stimulates FGF23 transcription.

Recent studies revealed that the administration of ferric citrate hydrate $(\mathrm{FCH})$ reduces intact FGF23 levels in pre-dialysis CKD patients $[19,20]$. FCH administration increased serum iron parameters and decreased phosphate levels $[19,20]$. Because treatment with oral phosphate binders other than FCH also decreases serum FGF23 levels in CKD patients with hyperphosphatemia, presumably by inhibiting intestinal phosphate absorption [21], it is not clear whether oral iron supplementation influenced serum FGF23 levels in those trials [19, 20].

The aim of the current prospective clinical trial was to elucidate the effects of oral iron supplementation on serum FGF23 levels in CKD patients with iron deficiency. Although FGF23 is a key player in CKD mineral and bone disorder and influences mortality in CKD patients, the regulation of FGF23 has not been fully clarified. Elucidating whether oral iron supplementation influences FGF23 transcription and degradation is important in order to understand the regulation of FGF23. This is the first study to evaluate the influence of oral iron on serum FGF23 in hemodialysis (HD) patients.

\section{Methods}

Study Population and Design

We enrolled 28 patients at Ojiya General Hospital. The patients were 20 years of age or older and had been maintained for at least 1 year with HD treatment ( 3 sessions per week of $>4 \mathrm{~h}$ ). All patients were treated with standard HD mode. The dialysate calcium ion concentration was $3.0 \mathrm{mEq} / \mathrm{l}$, and this value did not change over the 12-week period. The inclusion criteria were as follows: (1) hyperphosphatemia (iP $>6.0 \mathrm{mg} / \mathrm{dl}$ if patients were not treated with phosphate binders) that was treated with sevelamer- $\mathrm{HCl}$ and (2) iron deficiency, defined as a serum ferritin level $<100 \mathrm{ng} / \mathrm{ml}$ or serum ferritin level $100-300 \mathrm{ng} / \mathrm{ml}$ and transferring saturation (TSAT) $<20 \%$ [21]. The exclusion criteria were as follows: (1) patients with cancer, hematological disease or an active infection and (2) patients whose serum phosphate level was $<3.5 \mathrm{mg} / \mathrm{dl}$.

The study protocol was performed in accordance with the ethical guidelines of the Declaration of Helsinki and was approved by the human research committee at our institution (authorization No. 1401). Written informed consent was obtained from all participants. The study is registered with the UMIN Clinical Trials Registry (No. 000013972).

This study was a prospective, open-label interventional study. Patients who were treated with intravenous saccharated ferric oxide were required to discontinue treatment 4 weeks prior to commencement of the study. At trial initiation, the phosphate binder was changed from sevelamer- $\mathrm{HCl}$ to $\mathrm{FCH}$ (Torii Pharmaceutical, Co., Ltd., Tokyo, Japan) for all patients. The conversion rate from sevelamer- $\mathrm{HCl}$ to $\mathrm{FCH}$ was set at 1:0.45 to maintain the phosphate level. The dosages of VDRA, other phosphate binders, cinacalcet $\mathrm{HCl}$ and dialysate were not changed during the study period.

\section{Laboratory Testing}

Blood samples were obtained at the start of the dialysis session for baseline measurements and at weeks 3 and 12. Serum phosphorus, calcium, magnesium, alkaline phosphatase, iron, TSAT, ferritin, hemoglobin and C-reactive protein were measured by using standard methods. Serum calcium levels were corrected for albumin concentration by using the Payne's formula. Serum intact PTH levels were measured by using a second-generation PTH assay (Architect; Abbott Japan Co., Ltd., Tokyo, Japan). Serum intact FGF23 and C-term FGF23 levels were determined by using a sandwich ELISA kit (Immutopics International, San Clemente, Calif., USA). Serum $1,25(\mathrm{OH})_{2} \mathrm{D}$ was measured by using a radioimmunoassay (SRL, Tokyo, Japan).

\section{Statistical Analysis}

Intact FGF23, C-term FGF23 and intact PTH are expressed as the median (interquartile range); all other parameters are expressed as the mean \pm SD. The data in each time point were compared by using the Wilcoxon signed-rank test. Because serum intact FGF23 and C-term FGF23 were not normally distributed, 
we analyzed log-transformed values in the analyses. Statistical analysis was performed by using JMP 11.0.0 (SAS Institute, Cary, N.C., USA). A p value of $<0.05$ was considered statistically significant.

\section{Results}

\section{Clinical Characteristics}

A total of 28 patients were enrolled in the study. One patient was withdrawn because of diarrhea caused by FCH; therefore, 27 patients were included in the final analysis. The patients' baseline characteristics are shown in table 1 . The serum ferritin levels were lower than 100 $\mathrm{ng} / \mathrm{ml}$ in 26 patients, and the TSAT was lower than $20 \%$ in 15 patients. All patients were diagnosed as iron deficient.

\section{Effect of FCH on Iron-Related Factors and Anemia}

Serum iron, TSAT and serum ferritin levels were significantly elevated over the study period (TSAT: $20.4 \pm$ $8.4 \%$ at baseline, $32.4 \pm 16.2 \%$ at 3 weeks, $33.5 \pm 13.2 \%$ at 12 weeks; serum ferritin: $25.6 \pm 24.3 \mathrm{ng} / \mathrm{ml}$ at baseline, $43.2 \pm 21.7 \mathrm{ng} / \mathrm{ml}$ at 3 weeks, $55.8 \pm 33.5 \mathrm{ng} / \mathrm{ml}$ at 12 weeks; fig. 1). At 12 weeks, 4 patients were no longer considered iron deficient, and 23 patients remained iron deficient. Although the darbepoetin dose was decreased, the hemoglobin levels became significantly elevated with improvement of iron deficiency $(10.6 \pm 1.0 \mathrm{~g} / \mathrm{dl}$ at baseline, $11.3 \pm 1.0 \mathrm{~g} / \mathrm{dl}$ at 3 weeks and $12.3 \pm 1.6 \mathrm{~g} / \mathrm{dl}$ at 12 weeks).

\section{Effect of FCH on CKD Mineral and Bone}

Disorder-Related Parameters

The phosphate levels remained stable (table 2). The intact FGF23 levels were 2,000 $(1,300.0-3,471.4) \mathrm{pg} / \mathrm{ml}$ at baseline, and these levels decreased to 2,085.7 (1,442.9$3,228.6) \mathrm{pg} / \mathrm{ml}(\mathrm{p}=0.49)$ at 3 weeks and to $1,771.43$ $(1,142.9-2,342.9) \mathrm{pg} / \mathrm{ml}(\mathrm{p}=0.01)$ at 12 weeks (fig. 2). The C-term FGF23 levels were 1,608.7 (634.8-2,308.7) $\mathrm{RU} / \mathrm{ml}$ at baseline, and these levels decreased to $1,495.6$ $(773.9-2,139.1) \mathrm{RU} / \mathrm{ml}(\mathrm{p}=0.79)$ at 3 weeks and to $1,165.2$ (626.1-1,547.8) RU/ml ( $\mathrm{p}=0.007)$ at 12 weeks (fig. 3). The ratios of intact FGF23 to C-term FGF23 were $1.078 \pm$ 0.088 at baseline, $1.072 \pm 0.041$ at week 3 and $1.080 \pm$ 0.048 at week 12 . No significant differences were found in these ratios (fig. 4). The intact PTH levels were 96 (65125) $\mathrm{pg} / \mathrm{ml}$ at baseline, with a significant increase to 173 $(114-283) \mathrm{pg} / \mathrm{ml}$ at 12 weeks $(\mathrm{p}<0.001$; fig. 5). The $1,25(\mathrm{OH})_{2} \mathrm{D}$ levels remained unchanged in both patients with and without active vitamin D (table 2).

FCH Decreases FGF23

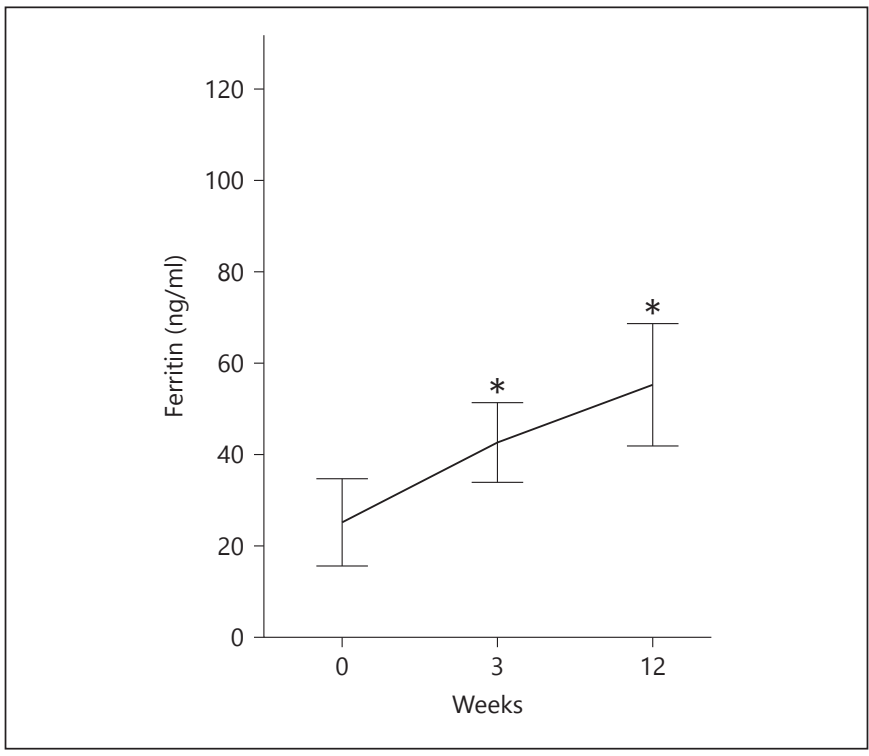

Fig. 1. Mean ferritin level after switching from sevelamer- $\mathrm{HCl}$ to $\mathrm{FCH}$. The error bars represent the SD. ${ }^{*} \mathrm{p}<0.001$ compared with 0 weeks.

Table 1. Baseline characteristics of the study participants

\begin{tabular}{lc}
\hline Characteristic & All patients $(\mathrm{n}=27)$ \\
\hline Sex, M/F & $18 / 9$ \\
Mean age, years & $62.6 \pm 15.7$ \\
Cause of ESRD (DM/non-DM) & $7 / 20$ \\
Dialysis duration, years & $12.6 \pm 7.9$ \\
Dialysis time, h/session & $4.28 \pm 0.38$ \\
Dialysate calcium ion, mEq/1 & 3.0 \\
Use of darbepoetin, $\mu \mathrm{g} /$ week & $24.7 \pm 21.0$ \\
Use of VDRA & \\
$\quad$ Intravenous calcitriol & 13 \\
$\quad$ Oral alfacalcidol & 1 \\
$\quad$ Non user & 13 \\
Use of cinacalcet HCl & 13 \\
\hline
\end{tabular}

$\mathrm{ESRD}=$ End-stage renal disease; $\mathrm{DM}=$ diabetes mellitus.

\section{Discussion}

This trial showed that, in HD patients, switching from sevelamer-HCl to FCH decreased both intact and C-term FGF23 levels, while intact PTH levels were elevated. The iron load would have been the main cause of altered circulating FGF23 levels due to FCH administration because the phosphate levels did not change.

Wolf et al. [22] compared the effects of intravenous iron in the form of ferric carboxymaltose (FCM) with iron dextran on serum FGF23 levels in women with iron-deficiency 
Table 2. Laboratory data during administration with FCH

\begin{tabular}{lccc}
\hline & Baseline & Week 3 & Week 12 \\
\hline Phosphorus, mg/dl & $5.89 \pm 1.45$ & $5.65 \pm 1.37$ & $5.54 \pm 1.35$ \\
Calcium, mg/dl & $9.40 \pm 0.57$ & $9.46 \pm 0.60$ & $9.37 \pm 0.87$ \\
Magnesium, mg/dl & $2.96 \pm 0.51$ & $2.97 \pm 0.53$ & $2.93 \pm 0.57$ \\
1,25(OH) ${ }_{2} \mathrm{D}, \mathrm{pg} / \mathrm{ml}$ & & & \\
$\quad$ User of VDRA (n $=14)$ & $11.42 \pm 4.75$ & $13.11 \pm 5.48$ & $11.08 \pm 4.72$ \\
$\quad$ Non user $(\mathrm{n}=13)$ & $6.23 \pm 2.93$ & $7.37 \pm 3.86$ & $7.11 \pm 2.48$ \\
Intact PTH, pg/ml & $114.0 \pm 101.6$ & $139.3 \pm 107.0^{* *}$ & $206.4 \pm 130.4^{* *}$ \\
Iron, $\mu$ g/dl & $58.7 \pm 22.9$ & $87.6 \pm 49.4^{*}$ & $77.6 \pm 28.9^{*}$ \\
TSAT, \% & $20.4 \pm 8.4$ & $32.4 \pm 16.2^{*}$ & $33.5 \pm 13.2^{* *}$ \\
Ferritin, ng/ml & $25.6 \pm 24.3$ & $43.2 \pm 21.7^{* *}$ & $55.8 \pm 33.5^{* *}$ \\
Hemoglobin, g/dl & $10.6 \pm 1.0$ & $11.3 \pm 1.0^{* *}$ & $12.3 \pm 1.6^{* *}$ \\
ALP, U/l & $249.2 \pm 86.0$ & $244.6 \pm 82.4$ & $244.5 \pm 83.2$ \\
CRP, mg/dl & $0.26 \pm 0.42$ & $0.39 \pm 0.88$ & $0.36 \pm 0.55$ \\
BUN, mg/dl & $60.1 \pm 14.5$ & $59.1 \pm 9.9$ & $58.4 \pm 11.3$ \\
Cr, mg/dl & $11.9 \pm 2.5$ & $12.4 \pm 2.6$ & $12.1 \pm 2.8$ \\
Kt/V & $1.33 \pm 0.17$ & $1.32 \pm 0.17$ & $1.33 \pm 0.19$ \\
FCH, mg/day & $1,175.9 \pm 595.7$ & $1,148.1 \pm 560.1$ & $1,148.1 \pm 560.1$ \\
Darbepoetin, $\mu \mathrm{gg} /$ week & $24.7 \pm 21.0$ & $24.7 \pm 21.0$ & $21.0 \pm 18.1$ \\
\hline
\end{tabular}

${ }^{*} \mathrm{p}<0.05,{ }^{* *} \mathrm{p}<0.001$, as compared with baseline.

$\mathrm{ALP}=$ Alkaline phosphatase; $\mathrm{BUN}=$ blood urea nitrogen; CRP $=\mathrm{C}$-re active protein; $\mathrm{Kt} / \mathrm{V}=$ single-pool Kt/V.

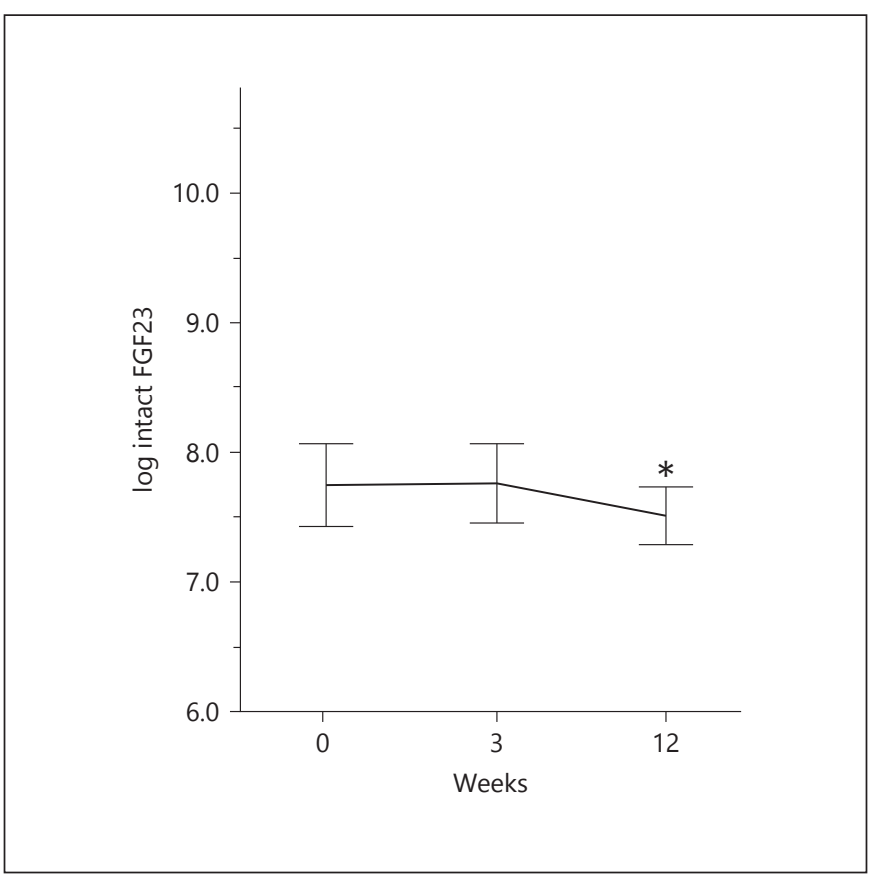

Fig. 2. Median log of intact FGF23 after switching from sevelamer$\mathrm{HCl}$ to $\mathrm{FCH}$. The error bars represent the interquartile range. ${ }^{*} \mathrm{p}=$ 0.01 compared with 0 weeks.

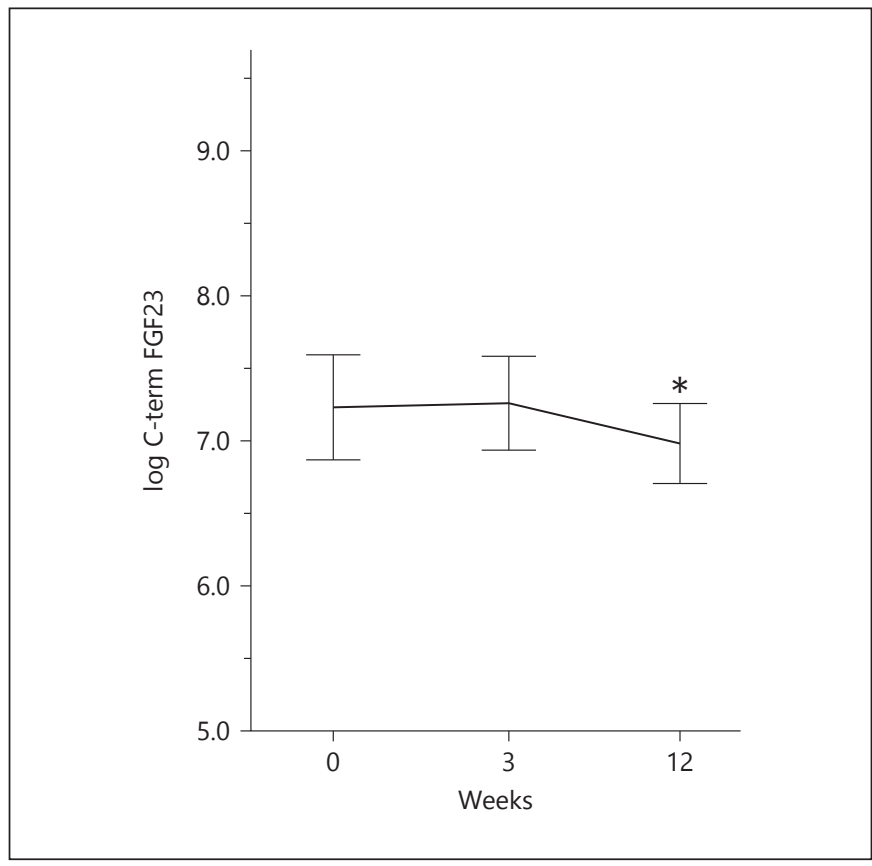

Fig. 3. Median log of C-term FGF23 after switching from sevelamer- $\mathrm{HCl}$ to $\mathrm{FCH}$. The error bars represent the interquartile range. $* \mathrm{p}=0.007$ compared with 0 weeks.

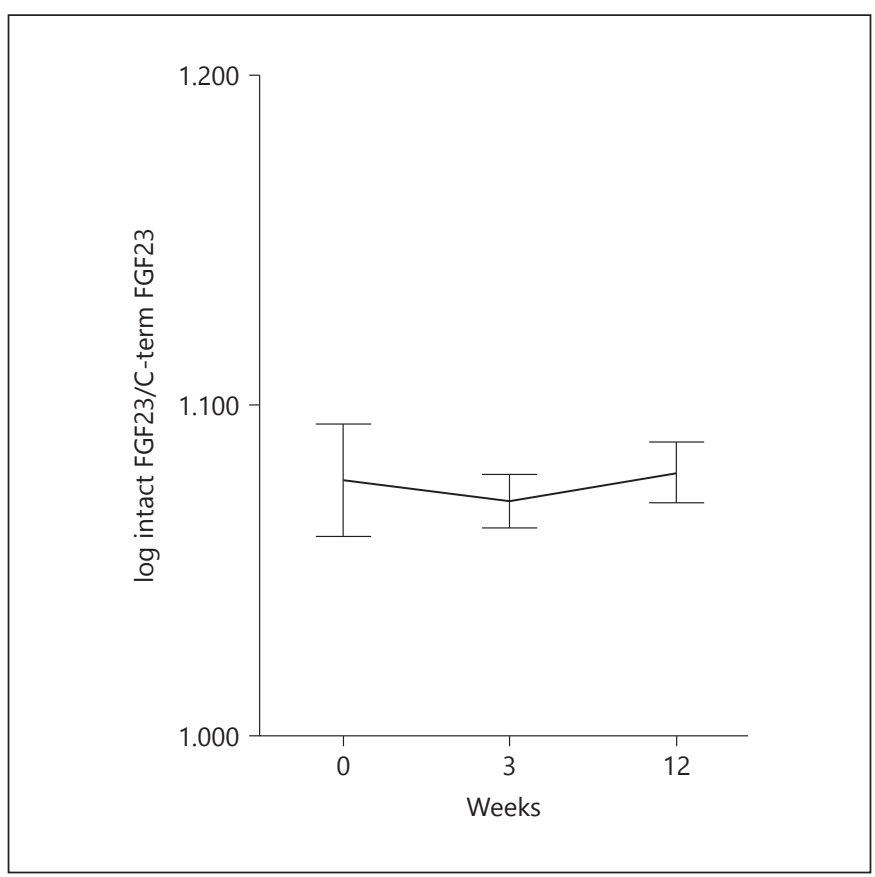

Fig. 4. Mean log of intact FGF23/log of C-term FGF23 after switching from sevelamer- $\mathrm{HCl}$ to $\mathrm{FCH}$. The error bars represent the SD. 


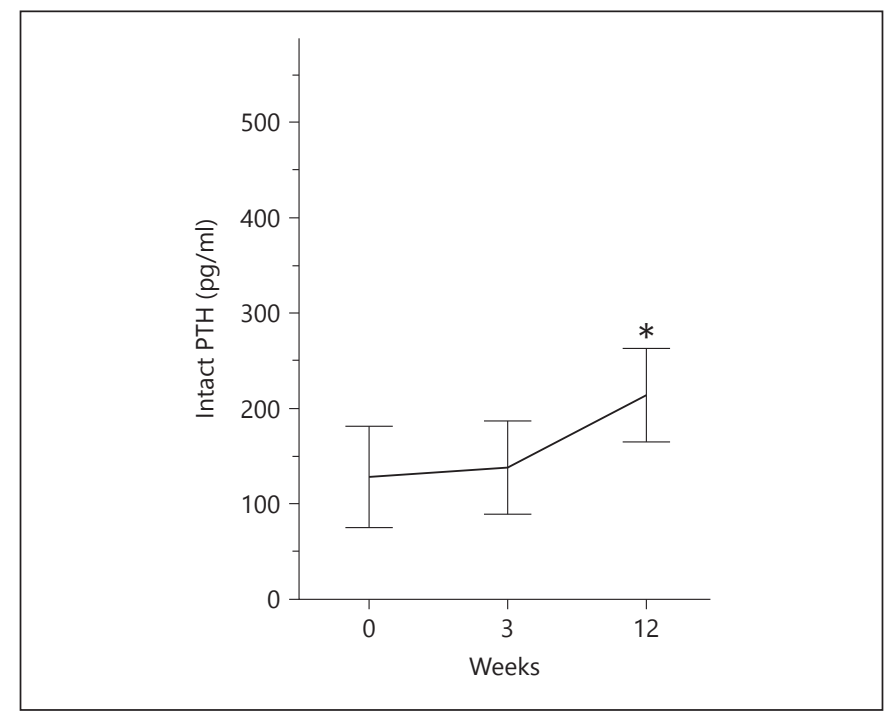

Fig. 5. Median intact PTH level after switching from sevelamer$\mathrm{HCl}$ to $\mathrm{FCH}$. The error bars represent the interquartile range. ${ }^{*} \mathrm{p}<$ 0.001 compared with 0 weeks.

anemia. Although both intravenous FCM and iron dextran decreased serum C-term FGF23 levels, FCM increased serum intact FGF23 levels and decreased serum phosphate levels despite no change in iron dextran. Thus, these authors hypothesized that FCM and iron dextran could reduce FGF23 transcription, but that the causative agents were the carbohydrate moieties of FCM rather than iron dextran, and the effect was due to inhibition of FGF23 degradation.

In the current study, switching to administration of $\mathrm{FCH}$ from sevelamer- $\mathrm{HCl}$ reduced intact FGF23 and Cterm FGF23. The iron elements of FCH might suppress the transcription of FGF23 in osteocytes. Intact FGF23 represents full-length FGF23, and C-term FGF23 represents full-length FGF23 and the C-terminal fragment. Therefore, the ratio of intact to C-term FGF23 indicates the amount of degradation of full-length FGF23. The ratio of intact to C-term FGF23 did not change, suggesting that oral intake of FCH has less influence on FGF23 degradation. A recent study, which evaluated the chronic effect of iron supplementation, showed that the role of iron on the degradation of circulating intact FGF23 might differ between the acute and the chronic phases of iron-deficiency anemia (David et al. [13] TH-OR102, ASN2014). This finding may help to explain why the suppression of FGF23 production had a greater impact than the suppression of FGF23 degradation in our HD patients with iron deficiency.

Reduction of FGF23 resulted in elevation of intact PTH levels in the current study. The relationship between
FGF23 and PTH is controversial. FGF23 suppresses the synthesis of PTH through its direct action on the parathyroid glands $[23,24]$. However, the relationship between FGF23 and PTH is not fully understood, as the regulation of FGF23 and PTH is complex, and indirect relationships via VDRA and/or phosphate balance exist. In the current study, the decreased direct suppression effect of FGF23 on the parathyroid glands may have caused PTH elevation because the serum phosphate, calcium and $1,25(\mathrm{OH})_{2} \mathrm{D}$ levels were constant. Oral treatment with FCH modestly increased serum intact PTH levels in HD patients, although it reduced phosphate levels [25]. It is possible that reduction of FGF23, which is caused by oral treatment with $\mathrm{FCH}$, directly influences elevation of PTH levels. Takeda et al. [26] reported that serum PTH levels decrease with elevation of FGF23 in HD patients. These previous studies suggest that FGF23 and PTH form a negative endocrine feedback loop.

Although PTH has been recognized as a uremic toxin since the 1970s [27], modern clinical studies have reported surprisingly limited impact of elevated PTH levels on mortality in CKD patients [28-30]. Other studies demonstrated that increased FGF23 predicted mortality and cardiovascular events in CKD patients $[8,9]$. If circulating FGF23 and PTH levels generally run counter to each other, the harm of elevated PTH levels might be offset by decreased FGF23 levels. Therefore, data from future studies investigating the mortality risk of PTH levels in CKD patients should be considered with regard to FGF23 levels.

This study has some limitations. First, no control patients were used; thus, a crossover study will be required to confirm the results. Second, as this was a small openlabel trial of short duration, conclusions about the longterm efficacy cannot be extrapolated. Further studies are required for confirming whether iron supplementation per se is capable to reduce the circulating FGF23 levels.

In conclusion, in HD patients with iron deficiency, switching the phosphate binder from sevelamer- $\mathrm{HCl}$ to FCH decreased serum FGF23 levels and increased serum PTH levels, despite the fact that the phosphate levels remained unchanged. Oral iron administration possibly reduces serum FGF23 levels independently of phosphate and VDRA. The reduction of FGF23 caused by FCH directly increased serum PTH levels.

\section{Disclosure Statement}

J.J.K. and I.N. received lecturer fee from Torii Pharmaceutical Co., Ltd. 


\section{References}

$1 \mathrm{Yu} \mathrm{X}$, White KE: FGF23 and disorders of phosphate homeostasis. Cytokine Growth Factor Rev 2005;16:221-232.

2 Wolf M: Update on fibroblast growth factor 23 in chronic kidney disease. Kidney Int 2012; 82:737-747.

3 Shigematsu T, Kazama JJ, Yamashita T, Fukumoto S, Hosoya T, Gejyo F, Fukagawa M: Possible involvement of circulating fibroblast growth factor 23 in the development of secondary hyperparathyroidism associated with renal insufficiency. Am J Kidney Dis 2004;44: 250-256.

4 Nakanishi S, Kazama JJ, Nii-Kono T, Omori K, Yamashita T, Fukumoto S, Gejyo F, Shigematsu T, Fukagawa M: Serum fibroblast growth factor-23 levels predict the future refractory hyperparathyroidism in dialysis patients. Kidney Int 2005;67:1171-1178.

5 Fukagawa M, Nii-Kono T, Kazama JJ: Role of fibroblast growth factor 23 in health and in chronic kidney disease. Curr Opin Nephrol Hypertens 2005;14:325-329.

6 Gutiérrez OM, Mannstadt M, Isakova T, Rauh-Hain JA, Tamez H, Shah A, Smith K, Lee H, Thadhani R, Jüppner H, Wolf M: Fibroblast growth factor 23 and mortality among patients undergoing hemodialysis. $\mathrm{N}$ Engl J Med 2008;359:584-592.

7 Isakova T, Xie H, Yang W, Xie D, Anderson AH, Scialla J, Wahl P, Gutiérrez OM, Steigerwalt S, He J, Schwartz S, Lo J, Ojo A, Sondheimer J, Hsu CY, Lash J, Leonard M, Kusek JW, Feldman HI, Wolf M; Chronic Renal Insufficiency Cohort (CRIC) Study Group: Fibroblast growth factor 23 and risks of mortality and end-stage renal disease in patients with chronic kidney disease. JAMA 2011;305: 2432-2439.

8 Faul C, Amaral AP, Oskouei B, Hu MC, Sloan A, Isakova T, Gutiérrez OM, Aguillon-Prada R, Lincoln J, Hare JM, Mundel P, Morales A, Scialla J, Fischer M, Soliman EZ, Chen J, Go AS, Rosas SE, Nessel L, Townsend RR, Feldman HI, St John Sutton M, Ojo A, Gadegbeku C, Di Marco GS, Reuter S, Kentrup D, Tiemann K, Brand M, Hill JA, Moe OW, Kuro-O M, Kusek JW, Keane MG, Wolf M: FGF23 induces left ventricular hypertrophy. J Clin Invest 2011;121:4393-4408.

9 Di Marco GS, Reuter S, Kentrup D, Grabner A, Amaral AP, Fobker M, Stypmann J, Pavenstädt H, Wolf M, Faul C, Brand M: Treatment of established left ventricular hypertrophy with fibroblast growth factor receptor blockade in an animal model of CKD. Nephrol Dial Transplant 2014;29:2028-2035.

10 Antoniucci DM, Yamashita T, Portale AA: Dietary phosphorus regulates serum fibroblast growth factor-23 concentrations in healthy men. J Clin Endocrinol Metab 2006; 91:3144-3149.
11 Wolf M: Forging forward with 10 burning questions on FGF23 in kidney disease. J Am Soc Nephrol 2010;21:1427-1435.

12 Bhattacharyya N, Chong WH, Gafni RI, Collins MT: Fibroblast growth factor 23: state of the field and future directions. Trends Endocrinol Metab 2012;23:610-618.

13 David V, Dai B, Martin A, Huang J, Han X, Quarles LD: Calcium regulates FGF-23 expression in bone. Endocrinology 2013;154: 4469-4482.

14 López I, Rodríguez-Ortiz ME, Almadén Y, Guerrero F, de Oca AM, Pineda C, Shalhoub V, Rodríguez M, Aguilera-Tejero E: Direct and indirect effects of parathyroid hormone on circulating levels of fibroblast growth factor 23 in vivo. Kidney Int 2011;80:475-482.

15 Wolf M, White KE: Coupling fibroblast growth factor 23 production and cleavage: iron deficiency, rickets, and kidney disease. Curr Opin Nephrol Hypertens 2014;23:411419.

16 Farrow EG, Yu X, Summers LJ, Davis SI, Fleet JC, Allen MR, Robling AG, Stayrook KR, Jideonwo V, Magers MJ, Garringer HJ, Vidal R, Chan RJ, Goodwin CB, Hui SL, Peacock M, White KE: Iron deficiency drives an autosomal dominant hypophosphatemic rickets (ADHR) phenotype in fibroblast growth factor-23 (FGF23) knock-in mice. Proc Natl Acad Sci U S A 2011;108:E1146-E1155.

17 Imel EA, Peacock M, Gray AK, Padgett LR, Hui SL, Econs MJ: Iron modifies plasma FGF23 differently in autosomal dominant hypophosphatemic rickets and healthy humans. J Clin Endocrinol Metab 2011;96:3541-3549.

18 Braithwaite V, Prentice AM, Doherty C, Prentice A: FGF23 is correlated with iron status but not with inflammation and decreases after iron supplementation: a supplementation study. Int J Pediatr Endocrinol 2012; 2012:27.

19 Yokoyama K, Hirakata H, Akiba T, Fukagawa M, Nakayama M, Sawada K, Kumagai Y, Block GA: Ferric citrate hydrate for the treatment of hyperphosphatemia in nondialysisdependent CKD. Clin J Am Soc Nephrol 2014;9:543-552.

20 Block GA, Fishbane S, Rodriguez M, Smits G, Shemesh S, Pergola PE, Wolf M, Chertow GM: A 12-week, double-blind, placebo-controlled trial of ferric citrate for the treatment of iron deficiency anemia and reduction of serum phosphate in patients with CKD stages 3-5. Am J Kidney Dis 2015;65:728-736.

21 Koiwa F, Kazama JJ, Tokumoto A, Onoda N, Kato H, Okada T, Nii-Kono T, Fukagawa M, Shigematsu T; ROD21 Clinical Research Group: Sevelamer hydrochloride and calcium bicarbonate reduce serum fibroblast growth factor 23 levels in dialysis patients. Ther Apher Dial 2005;9:336-339.
22 Anker SD, Comin Colet J, Filippatos G, Willenheimer R, Dickstein K, Drexler H, Lüscher TF, Bart B, Banasiak W, Niegowska J, Kirwan BA, Mori C, von Eisenhart Rothe B, Pocock SJ, Poole-Wilson PA, Ponikowski P; FAIRHF Trial Investigators: Ferric carboxymaltose in patients with heart failure and iron deficiency. N Engl J Med 2009;361:2436-2448.

23 Wolf M, Koch TA, Bregman DB: Effects of iron deficiency anemia and its treatment on fibroblast growth factor 23 and phosphate homeostasis in women. J Bone Miner Res 2013; 28:1793-1803.

24 Ben-Dov IZ, Galitzer H, Lavi-Moshayoff V, Goetz R, Kuro-o M, Mohammadi M, Sirkis R, Naveh-Many T, Silver J: The parathyroid is a target organ for FGF23 in rats. J Clin Invest 2007;117:4003-4008

25 Krajisnik T, Björklund P, Marsell R, Ljunggren $\mathrm{O}$, Akerström $\mathrm{G}$, Jonsson $\mathrm{KB}$, Westin $\mathrm{G}$, Larsson TE: Fibroblast growth factor-23 regulates parathyroid hormone and 1alpha-hydroxylase expression in cultured bovine parathyroid cells. J Endocrinol 2007;195:125-131.

26 Yokoyama K, Akiba T, Fukagawa M, Nakayama M, Sawada K, Kumagai Y, Chertow GM, Hirakata H: Long-term safety and efficacy of a novel iron-containing phosphate binder, JTT-751, in patients receiving hemodialysis. J Ren Nutr 2014:24:261-267.

27 Takeda Y, Komaba H, Goto S, Fujii H, Umezu M, Hasegawa H, Fujimori A, Nishioka M, Nishi S, Fukagawa M: Effect of intravenous saccharated ferric oxide on serum FGF23 and mineral metabolism in hemodialysis patients. Am J Nephrol 2011;33:421-426.

28 Massry SG, Goldstein DA: Role of parathyroid hormone in uremic toxicity. Kidney Int Suppl 1978;8:S39-S42.

29 Block GA, Klassen PS, Lazarus JM, Ofsthun N, Lowrie EG, Chertow GM: Mineral metabolism, mortality, and morbidity in maintenance hemodialysis. J Am Soc Nephrol 2004; 15:2208-2218.

30 Kalantar-Zadeh K, Kuwae N, Regidor DL, Kovesdy CP, Kilpatrick RD, Shinaberger CS, McAllister CJ, Budoff MJ, Salusky IB, Kopple JD: Survival predictability of time-varying indicators of bone disease in maintenance hemodialysis patients. Kidney Int 2006;70:771780

31 Wald R, Sarnak MJ, Tighiouart H, Cheung AK, Levey AS, Eknoyan G, Miskulin DC: Disordered mineral metabolism in hemodialysis patients: an analysis of cumulative effects in the hemodialysis (HEMO) study. Am J Kidney Dis 2008;52:531-540.

32 Nemeth E: Iron regulation and erythropoiesis. Curr Opin Hematol 2008;15:169-175.

33 Kemna EH, Tjalsma H, Willems HL, Swinkels DW: Hepcidin: from discovery to differential diagnosis. Haematologica 2008;93:90-97. 